\title{
Evaluation of the Hydrodynamic Pressure Effect of Cylindrical Liquid Storage Tank on The Granular Soil Behavior Under Seismic Excitation
}

\author{
Ahmed A. Hussein $\mathbb{C}^{\mathrm{a}^{*}}{ }^{\text {, }}$, Mohammed A. Al-Neami ${ }^{\text {b }}{ }^{\mathrm{b}}$, Falah H. Rahil ${ }^{\mathrm{c}}$ \\ ${ }^{a}$ University of Technology, Baghdad, Iraq.42080@student.uotechnology.edu.iq \\ ${ }^{\text {b }}$ University of Technology, Baghdad, Iraq. 40008@uotechnology.edu.iq \\ `University of Technology, Baghdad, Iraq.40029@uotechnology.edu.iq \\ *Corresponding author.
}

Submitted: 28/04/2020

Accepted: 30/10/2020

Published: 25/01/2021

K E Y W O R D S

Earthquake, shake table, hydrodynamic pressure, cylindrical storage tank

\begin{abstract}
A B S T R A C T
Many liquid storage tanks around the world have been affected by earthquakes, and the seismic analysis of such tanks is much more complicated due to the Fluid-Structure Interaction. Besides, when the soil properties are taken into the consideration, the analysis with the FluidSoil-Structure Interaction becomes very complicated. In this paper, a series of shaking table tests are conducted on a model of the cylindrical water tank rested on dry granular soil and the equivalent load is considered to study the effect of hydrodynamic pressure generated in the storage water tank on the soil behavior. An experimental investigation of (1:100) scale model has been carried out on a shake table that was manufactured with specific mechanical parts and flexible laminar shear box. The preparation of the test included three cases in different relative densities (medium, dense, medium-dense). Three earthquake histories (Kobe, El-Centro and Ali Al-Gharbi) were implemented to study a wide range of the acceleration. The results showed that the acceleration at the bottom-depth of the soil column is slightly higher than at the mid-depth, while at the top portion of the soil column, the acceleration comparatively becomes less than that at the mid-depth. The settlement due to hydrodynamic pressure in the storage base tank is significantly reduced compared with results of nonhydrodynamic pressure in all cases of the acceleration history. In addition, the lateral stress at the surface gives higher than the stress at a depth equal to the diameter of the base tank.
\end{abstract}

\footnotetext{
How to cite this article: A. A. Hussein, M. A. Al-Neami and F. H. Rahil, "Evaluation of the Hydrodynamic Pressure Effect of Cylindrical Liquid Storage Tank on The Behavior of Granular Soil Under Seismic Excitation," Engineering and Technology Journal, Vol. 39, Part A, No. 01, pp. 64-78, 2021.

DOI: https://doi.org/10.30684/etj.v39i1A.1697

This is an open access article under the CC BY 4.0 license http://creativecommons.org/licenses/by/4.0
} 


\section{INTRODUCTION}

Cylindrical steel and reinforced concrete tanks are widely used as engineering structures to store water, fuel or the other liquids. The earthquake behavior of liquid storage tanks is very different to other structures. The dynamic interaction between fluid, structure, and soil is of great concern in many engineering problems. Each of the soil-structure interaction and fluid-structure interaction is separately a complex phenomenon for structures. In fact, the dynamic characteristics of the tank and its response to transient excitations are governed by several factors such as earthquake characteristics, the interaction between the fluid and the structure, and the soil-structure interaction along with their boundaries. Housner [1] proposed a simplified analytical solution in which the hydrodynamic pressures induced by the ground motions are separated into two parts as convective and impulsive components and are modeled as lumped added masses. Later, many studies considering the effect of fluid on the tank [2,3,4, and 5] have also been conducted using the model proposed by Housner. However, in all these analyses, the base of the tank is assumed to be fixed and the flexibility of soil is not accounted for the analysis. It is well known that the actual behavior of the tank not only depends on the stiffness of the tank, but also on the stiffness of the foundation and supporting soil. Kim et al. [6] presented a method for a cylindrical tank by considering the effects of the liquid and soil system in the frequency domain. Kianoush and Ghaemmaghami [7] also investigated the effect of soil-structure interaction on a tank filled with fluid for six types of soils. Chaithra et al. [8] considered the influence of flexibility of the soil on a tank filled with fluid is studied. In order to consider the effect of flexibility of the tank wall, the tank, soil, and fluid are modeled using finite elements. A similar investigation has been carried out by Chaithra et al. [8] To study the effect of soil-structure interaction for a Chi-Chi earthquake. Michel S. Chalhoub and James M., [9] found from the experimental case the results for two comparable cylindrical water tanks, then matched with a theoretical solution. The first tanks were connected to the earthquake simulator directly, and the second one was attached to the base of the scaled steel structure. They found the final motion of dynamic pressure and water level contain the term that depends on the ground acceleration corresponding to oscillation time history and excellent matching was found by using little modes. These conclusions can be applied directly to the prototype subjected to the main support excitation. Experimental investigation for a 1:4 scale model of cylindrical steel elevated water tank has been carried out by Chaduvulaa et al., [10] on the shake table, test procedure on elevated steel water tank contained mutual horizontal, vertical, and rocking motions, for artificial earthquake excitation $0.1 \mathrm{~g}$ and $0.2 \mathrm{~g}$ acceleration, with increasing rocking angle motion. The impulsive base shear and impulsive base moment value raised with increasing earthquake acceleration, while reducing with increasing angle of motion. Therefore, there is no significant effect of rocking motion on the water sloshing. It was observed of non-linearity in structure when the impulsive pressure of the tank reduces with increasing acceleration and increases with further rocking.

\section{EXPERIMENTAL INVESTIGATION}

The experimental study aims to clarify the behavior of soil under the water tank model during horizontal earthquake motions. Generally, the shake table plays an important role to simulate different earthquake shake histories and study their effects on the dry and saturated soils.

\section{Soil Properties}

The soils are used for the model tests were "Dyala Black Sand". Several tests were performed on sand with three different cases of medium, dense, and medium \& dense with relative density of (Dr=50 and 75) \% respectively. The conducted soil tests are carried out according to standards ASTM. The properties resulted from the implemented tests, and the used standard method on sand summarized in Table 1. 
TABLE I: physical properties and tests carried out on soils with standard.

\begin{tabular}{|c|c|c|c|}
\hline Soil Property & Medium sand & Dense sand & Standard \\
\hline Relative density $\mathrm{D}_{\mathrm{r}}(\%)$ & 50 & 75 & \\
\hline Maximum dry unit weight $(\mathrm{kN} / \mathrm{m} 3)$ & \multicolumn{2}{|c|}{19.25} & ASTM D4253 \\
\hline Minimum dry unit weight $\left(\mathrm{kN} / \mathrm{m}^{3}\right)$ & \multicolumn{2}{|c|}{16.41} & ASTM D4254 \\
\hline Dry unit weight $\left(\mathrm{kN} / \mathrm{m}^{3}\right)$ & 17.72 & 18.64 & \\
\hline Specific gravity & \multicolumn{2}{|c|}{2.665} & ASTM D854 \\
\hline Effective size $\mathrm{D}_{10}$ & \multicolumn{2}{|c|}{0.145} & \\
\hline Effective size $\mathrm{D}_{30}$ & \multicolumn{2}{|c|}{0.277} & \\
\hline Effective size $\mathrm{D}_{60}$ & \multicolumn{2}{|c|}{1.675} & ASTM D422 \\
\hline Coefficient of uniformity, $\mathrm{Cu}$ & \multicolumn{2}{|c|}{11.5} & \\
\hline Coefficient of curvature, $\mathrm{Cc}$ & \multicolumn{2}{|c|}{0.315} & \\
\hline Soil classification USCS & \multicolumn{2}{|c|}{ Poorly to well graded sand } & ASTM D2487 \\
\hline Soil color & \multicolumn{2}{|c|}{ Pale black } & \\
\hline Friction angle, deg. & 30 & 34 & ASTM D2434 \\
\hline
\end{tabular}

\section{Shaking table mechanical parts}

A shaking table used in this study was manufactured by Al Sammaraey [14] which consists of 10 $\mathrm{mm}$ steel plate thickness act as a platform, which combines motor flange, two steel channels and support bases for ball screw that carry the linear guides. A stiff rubber sheet with $10 \mathrm{~mm}$ thickness that enables the machine to be stacked on the floor and reduced any vibration transition was utilized to place the chassis on it. Figure 1 shows the shake table system and it can be seen that a ball screw shaft with a diameter of $40 \mathrm{~mm}$ with $40 \mathrm{~mm}$ lead; the total length of $750 \mathrm{~mm}$, and travel length of $602 \mathrm{~mm}$ was utilized to convert the rotational motion of the motor to a linear displacement. Each one of the revolutions is equivalent to a $40 \mathrm{~mm}$ linear displacement. Two brackets were used as a nut bracket for the ball screw and the others are designed to connect the bracket with the table through the load cell. Two linear guide rails of $1250 \mathrm{~mm}$ long are fixed to the chassis and each one has three blocks that screwed with a table consists of a square steel plate $(800 \times 800) \mathrm{mm}$ and $10 \mathrm{~mm}$ thickness, a fortified alongside with three steel strips of $10 \mathrm{~mm}$ thickness that links it to the linear guide blocks which allow it to slide freely over the chassis. The table is considered as the base that will introduce a shaking to the model attached over it. Servo motors provide a super performance alternative to other types of motors.

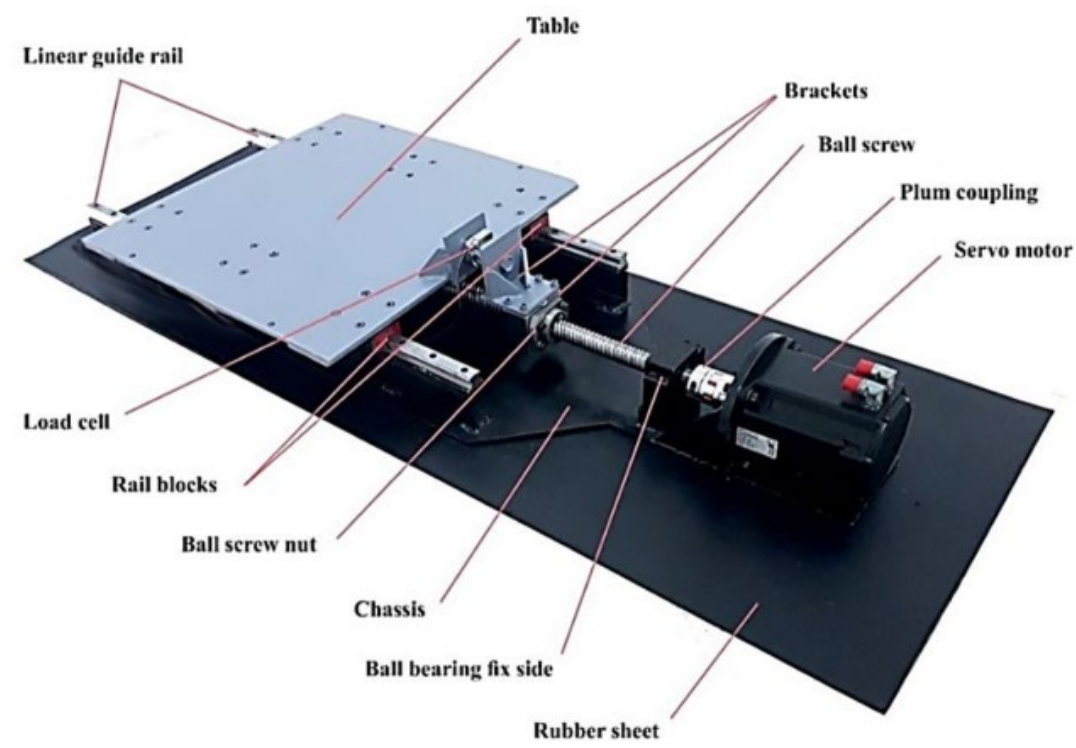

Figure 1: The shaking table system 


\section{SYSTEM SPECIFICATION}

The shake table simulates the earthquake condition to investigate the performance of the model with high quality, reliability, and cost efficiency. It is suitable for laboratories that perform research and component tests and do not require special capabilities that included in complex systems, in addition to quickly setup and installation into existing facilities.

\section{Flexible laminar shear box (FLSB)}

Flexible Laminar Shear Box (FLSB) shown in Figure 2 is a container utilized to hold the tested soil and foundation models. It was designed to reduce the influence of boundaries that are typically experienced when utilizing a fixed side box. FLSB designed so that the shear stiffness of the end walls matches that of the soil model, in addition, to simulate the conditions of the realistic behavior of soils as the wave reflection from the side boundary is weakened greatly due to the relative horizontal deformation of the laminae.

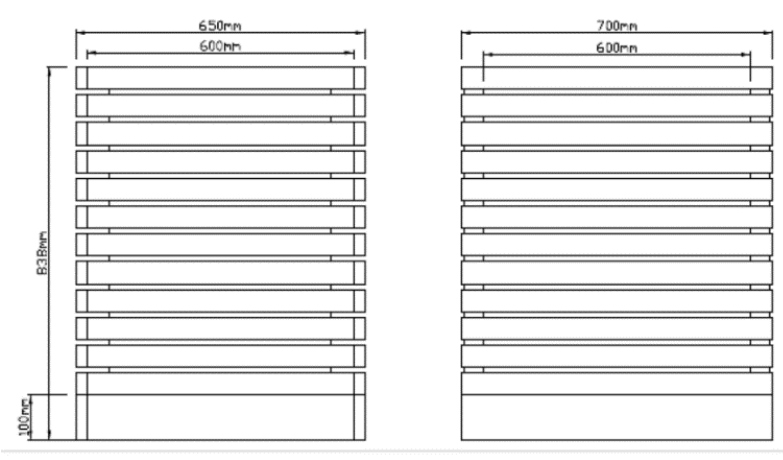

Figure 2: Flexible laminar shear box

The FLSB consists of 12 square steel laminae stacked, one above each other with rails that allow it to freely slide in one horizontal direction. The lamina was constructed from a steel tube with dimensions that are welded as a square frame with inner dimensions of $(600 \times 600) \mathrm{mm}$ and outer dimensions of $(700 \times 650) \mathrm{mm}$ with $50 \mathrm{~mm}$ in height for single lamina. The total height of the FLSB was $838 \mathrm{~mm}$. So, the tested soil model size was $(600 \times 600 \times 600) \mathrm{mm}$. The FLSB was installed on the table as it is shown in Figure 3 and to ensure a good limitation for the stress distribution of the footing to the box, Poulos and Davis [11], Steensen-Bach et al. [12] and Agarwal and Rana [13] reported that the size of the stress bulb zone with respect to depth is (1.5-2) B below the model footing and 1.5B away from the model footing (where B is the footing width). In the current study, the size of the stress bulb zone with respect to depth is $280 \mathrm{~mm}$ and $210 \mathrm{~mm}$ away from the footing and that adequate for the FLSB. A storage tank model with a weight of $1.5 \mathrm{~kg}$ block with an area of (153.86) $\mathrm{mm}^{2}$ and $100 \mathrm{~mm}$ in height (which equivalent to prototype full-scale model 1:100) dimensions of (diameter $14 \mathrm{~m}$ \&height $10 \mathrm{~m}$ ) was placed on the soil surface. However, this scale factor was selected for this model due to the wide diameter of the prototype (storage tank) $(10 \mathrm{~m})$ relative to the constraint of the available laminar box dimensions $(60 * 60 * 80) \mathrm{cm}$.

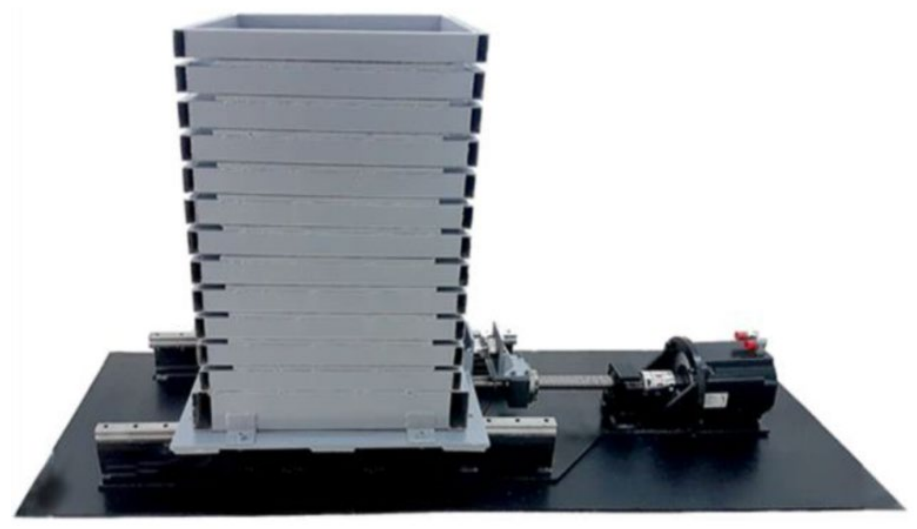

Figure 3: FLSB installed on the table 


\section{TEST PREPARATION}

After the shake components combined, the system setup was completed, and the experimental test is ready to be prepared. The sand was air-dried and poured into the storage barrel. After that, the sand was tamped into layers to the desired density as described in Figure 4.
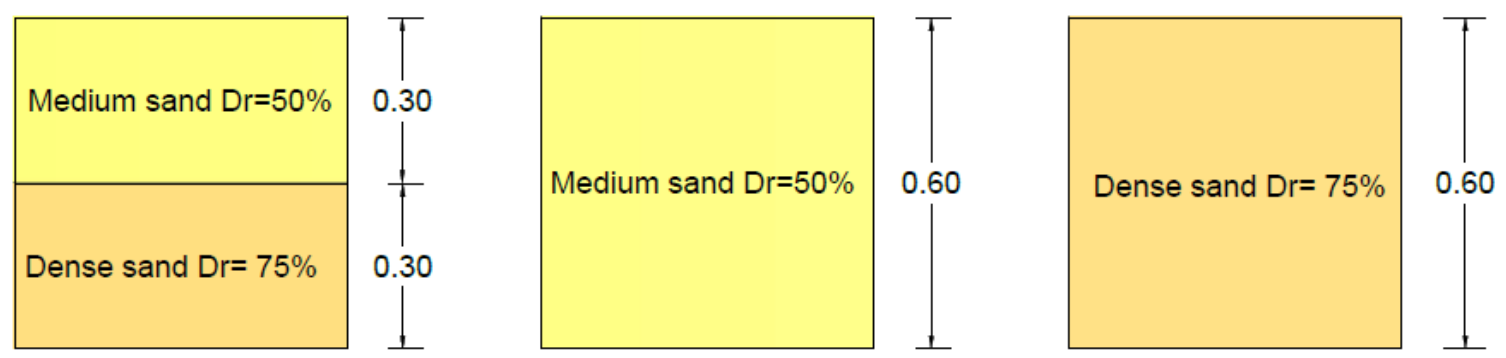

Figure 4: Cases of study of soil profile

Three cases of the soil profile were studied; single sandy layer case of $600 \mathrm{~mm}$ thickness with a medium relative density of $(50 \%)$, dense relative density $(75 \%)$ and two layers of the sand with medium and dense relative densities with thickness of 300-300 mm, as illustrated in Figure 4. In all sand layers, accelerometers were embedded through the prepared sand layer during tamp-layer construction in three depths $(140,280$ and 560) mm, the test layout is shown in Figure 5. After the soil profile was formed, the storage tank was placed on the center of the soil surface. Then, the accelerometer (Acc.), and lateral cell pressure (CP) were fixed in the soil in location was clarified in the Figure 5, while three displacement transducers were linked to the center of the storage tank across a screw nut.

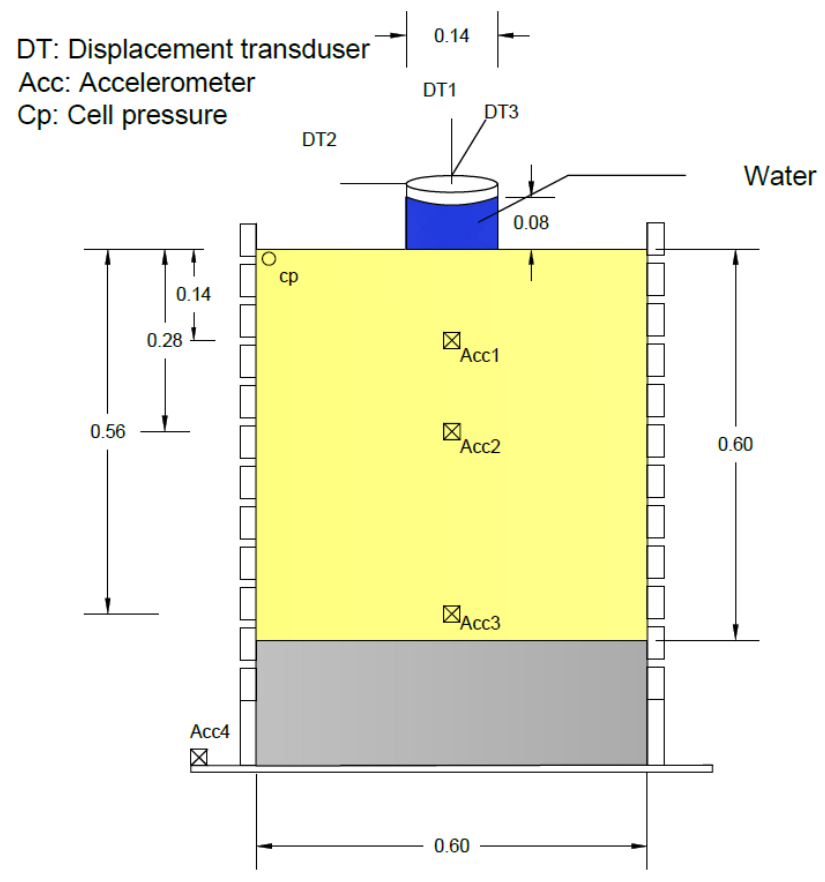

Figure 5: Test model layout

\section{TeSting Program For Shake table tests}

six shake table tests were conducted on the different soil conditions and soil properties such as sand density, layered subsoil. For more clarification, the testing program is illustrated in a flowchart in Figure 6. The test program was divided into two major parts, the first one was used storage tank partially full of water ( $8 \mathrm{~cm}$ from $10 \mathrm{~cm}$ height of the tank) and to clarify the effect of hydrodynamic on the tanks the other tank was used empty and filled with an equivalent weight of water. 


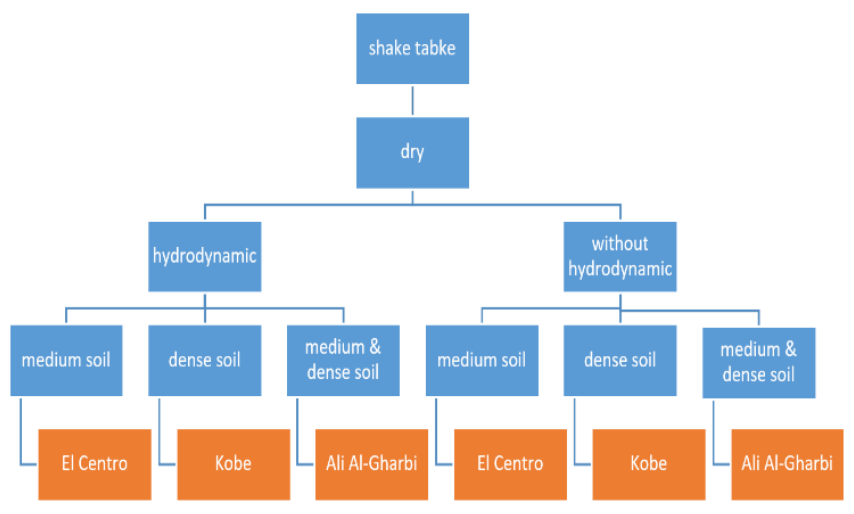

Figure 6: Flowchart for shake table test

\section{IMPLEMENTATION EARTHQUAKE DATA}

In order to study the effects of acceleration characteristics on the dry sandy soil, various real earthquake acceleration histories data were implemented. The real acceleration histories for Ali AlGharbi, El Centro and Kobe were utilized. Calibration was performed for these earthquakes by comparing input acceleration with considering full weight container and output acceleration during the same time, which presented very good compatibility. Table 2 presents the information for each earthquake data. Furthermore, due to the small value of the maximum acceleration of the Ali AlGharbi earthquake $(0.1 \mathrm{~g})$ and the significant scale factor $(1: 100)$, this acceleration has been amplified by multiplying it with four acceleration factors to impact the results in all cases. Figure 7 shows the studied cases of acceleration history.

TABLE II: The studied cases of acceleration history

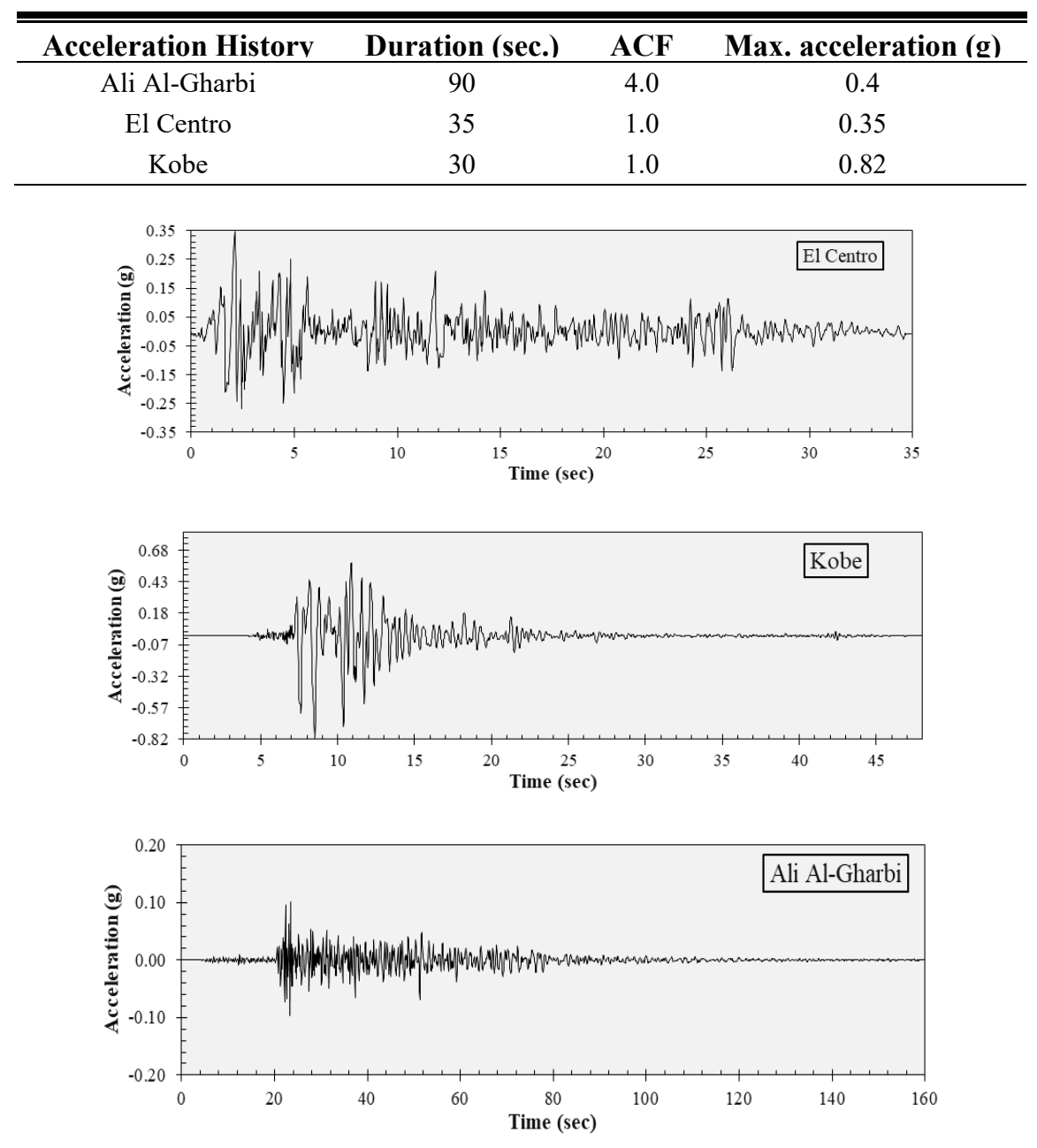

Figure 7: Acceleration history of the used earthquake 


\section{RESULTS AND DISCUSSIONS}

Test results have presented as a relationship between the studied various parameters against the time which including of the lateral displacement, tank settlement and lateral pressure. These parameters were obtained by using the earthquake shake table accelerometer, displacement transducer and lateral cell pressure located at the boundary of laminar shake on the surface and at a depth $\mathrm{B}$ of surface (B is the diameter of the base tank) in different depths in the soil layer as mentioned before and as illustrated in Figure 5. Besides, the values of the settlement, lateral X- and $\mathrm{Z}$-direction displacements (where the X-direction is the direction parallel to input acceleration direction and Z-direction is the direction perpendicular to X-direction) was presented in Figures 8-13.
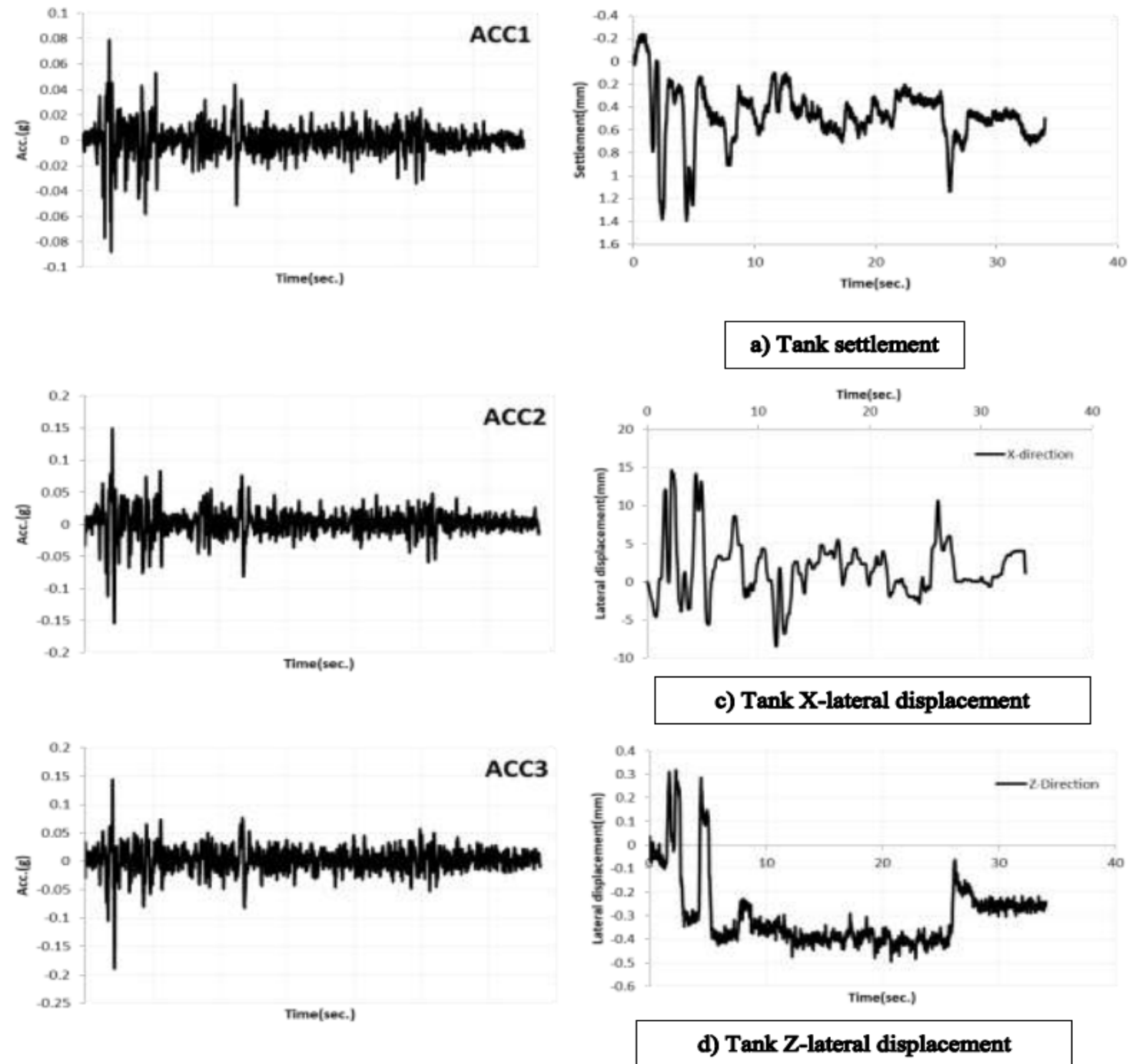


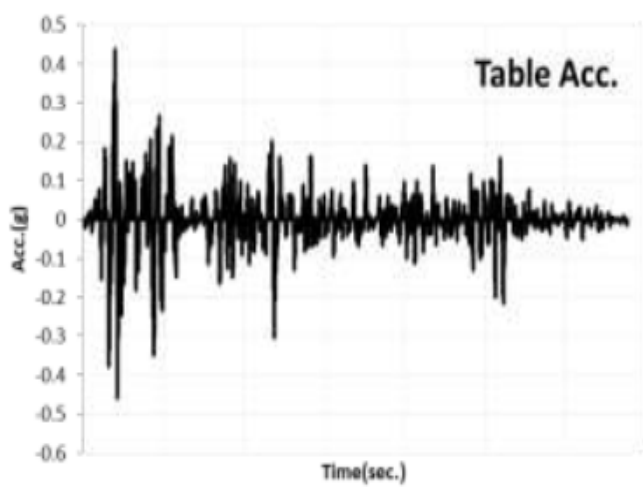

b) Acceleration

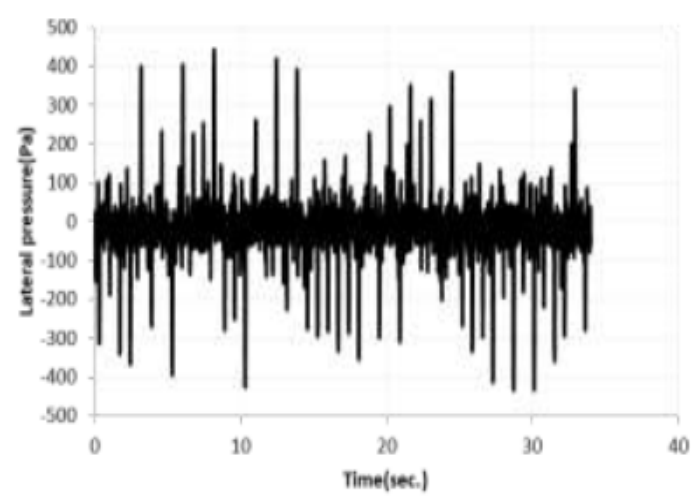

e) Tank lateral pressure at depth $=B$

Figure 8: Results for Hydrodynamic El-Centro earthquake with Medium sand layer, $(\mathrm{Dr}=\mathbf{5 0} \%$, $\mathrm{ACF}=\mathbf{1 . 0 )}$.

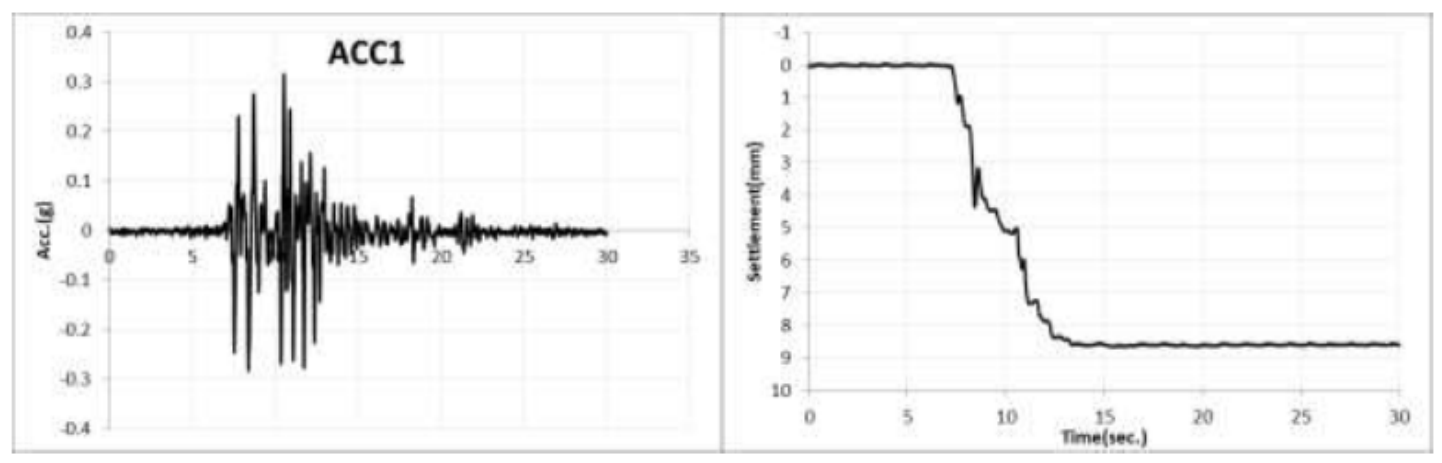

a) Tank settlement

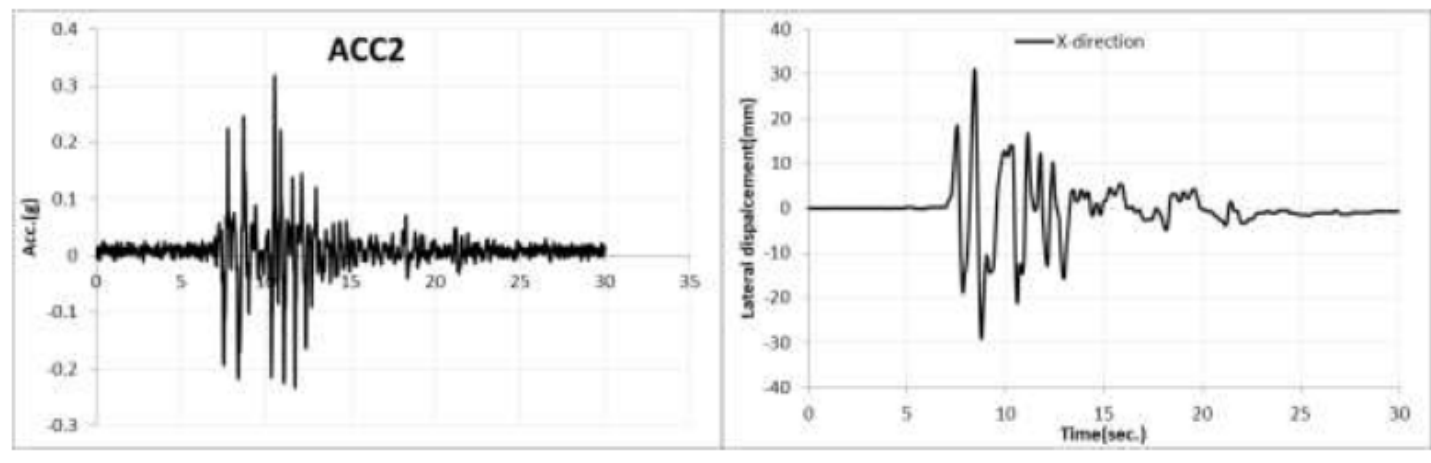

c) Tank X-lateral displacement 

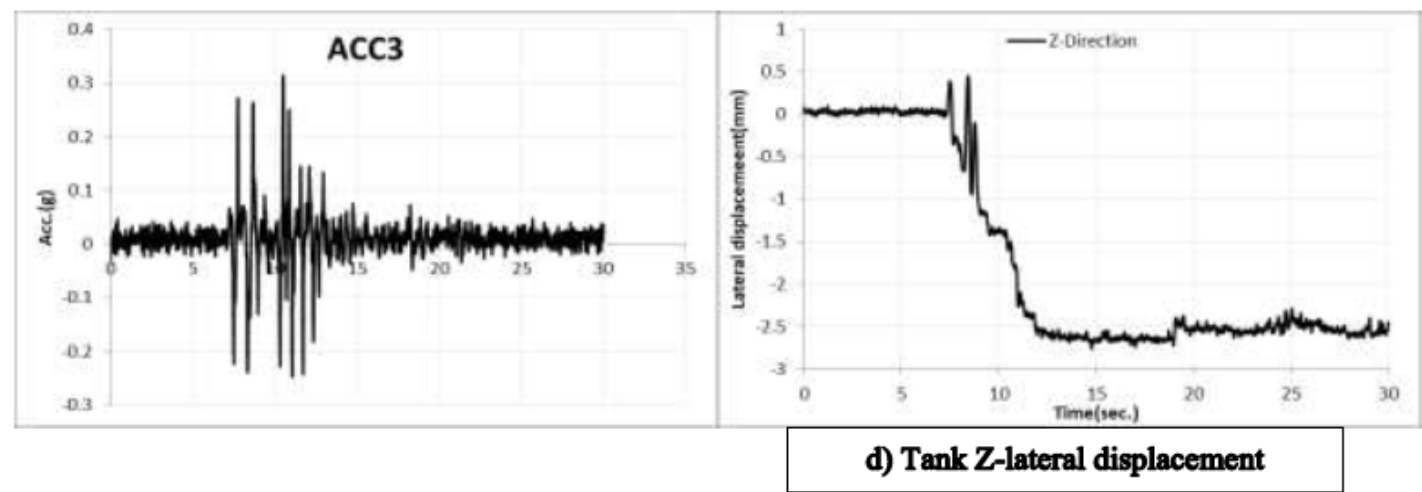

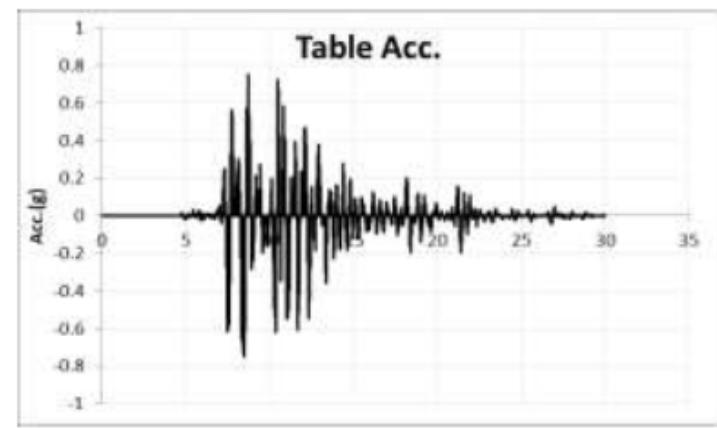

b) Acceleration

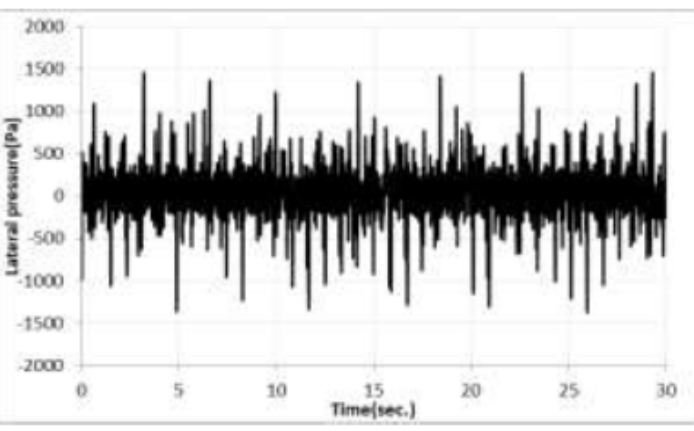

e) Tank lateral pressure at the surface

Figure 9: Results for Hydrodynamic Kobe earthquake with Dense sand layer, (Dr=75\%, ACF=1.0).
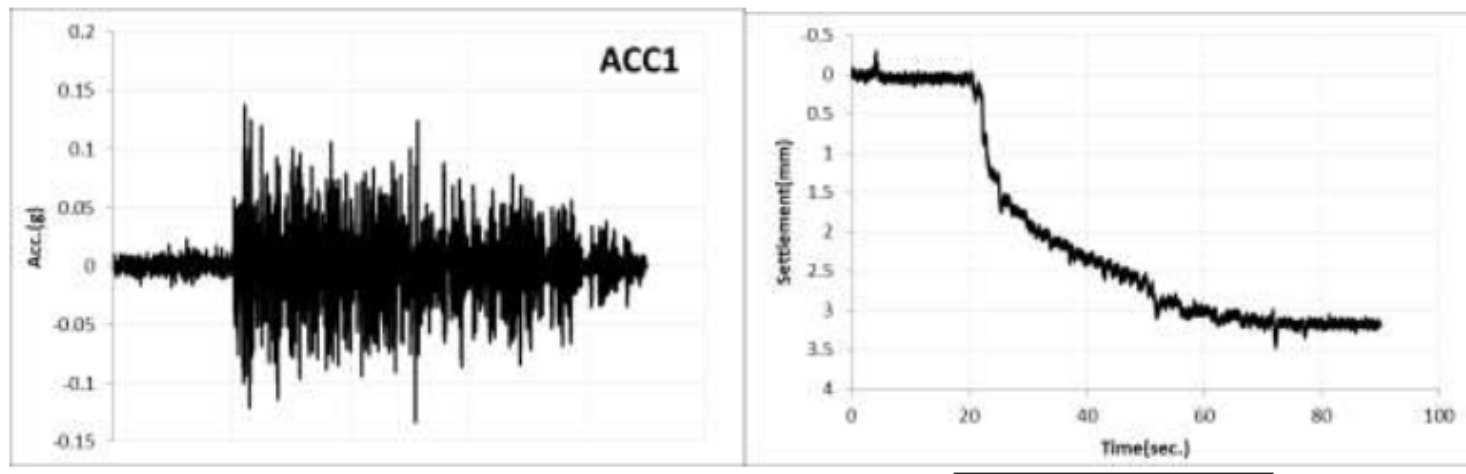

a) Tank settlement
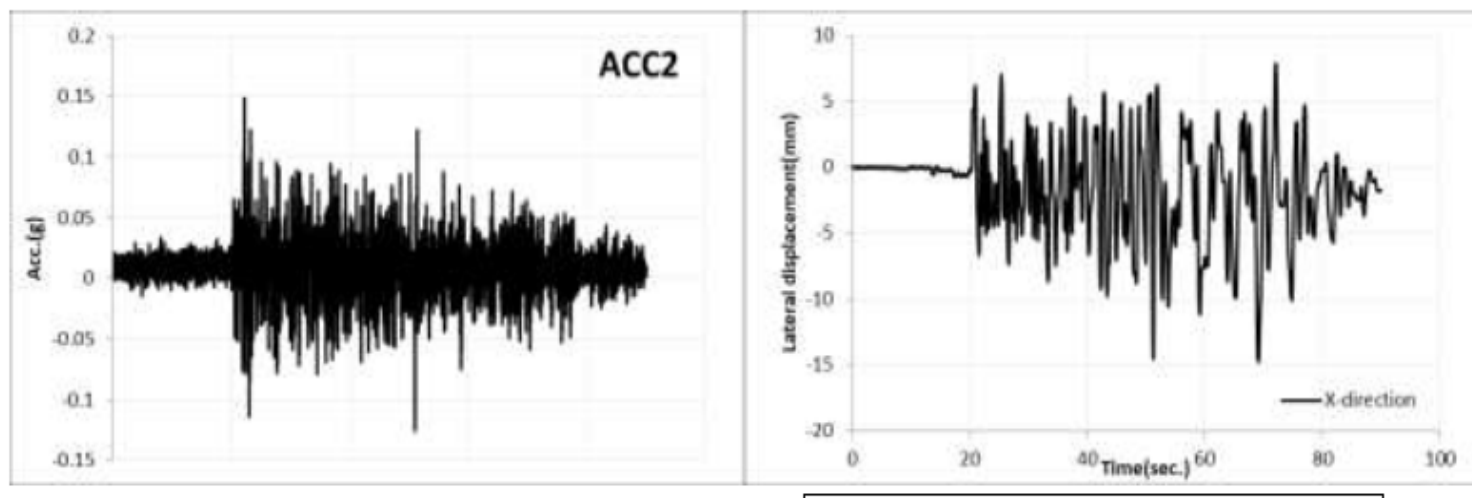

c) Tank X-lateral displacement 


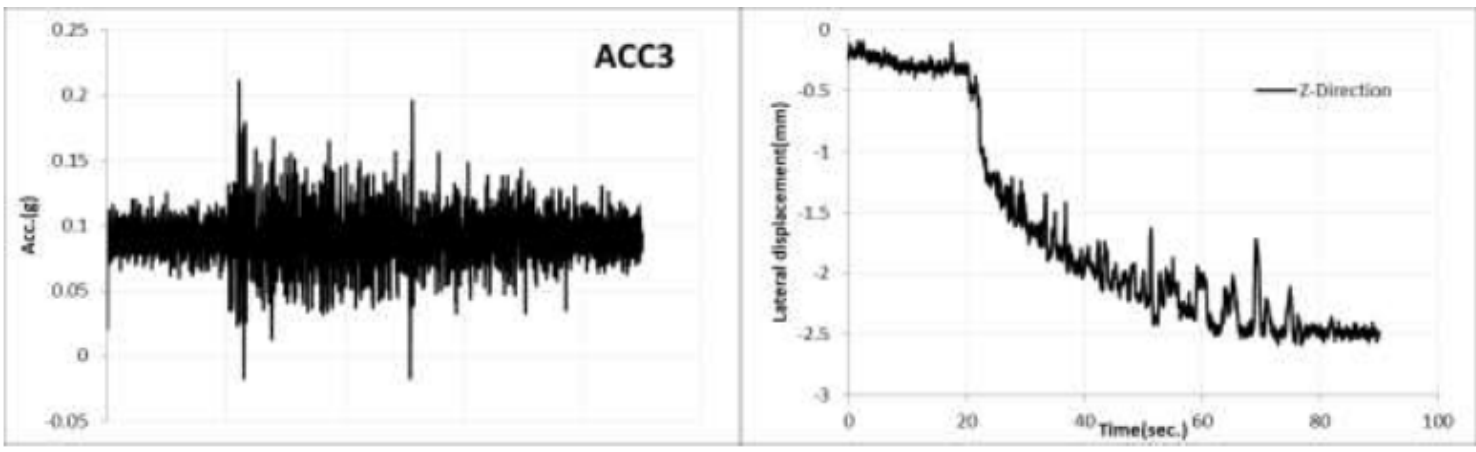

d) Tank Z-lateral displacement

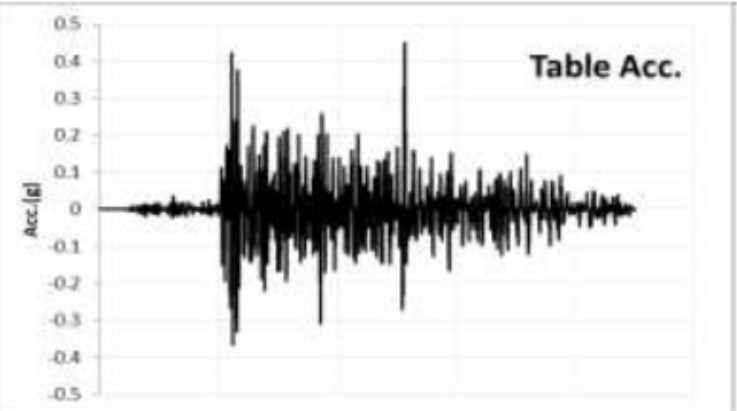

b) Acceleration

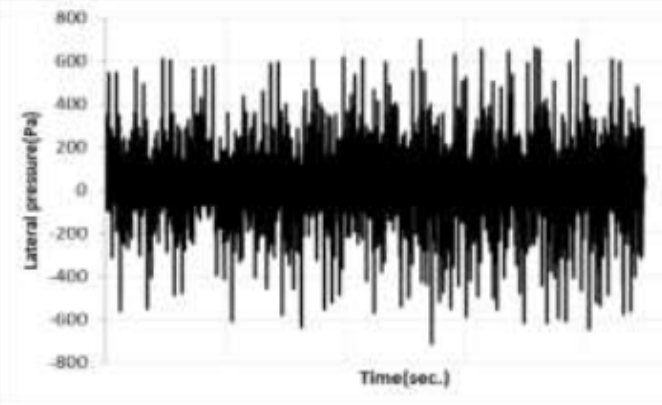

e) Tank lateral pressure at depth $=B$

Figure 10: Results for Hydrodynamic Ali Al-Gharbi earthquake with Medium \& Dense sand layer, $(\mathrm{Dr}=\mathbf{5 0} \%$, Dr=75\% ACF $=4.0)$.
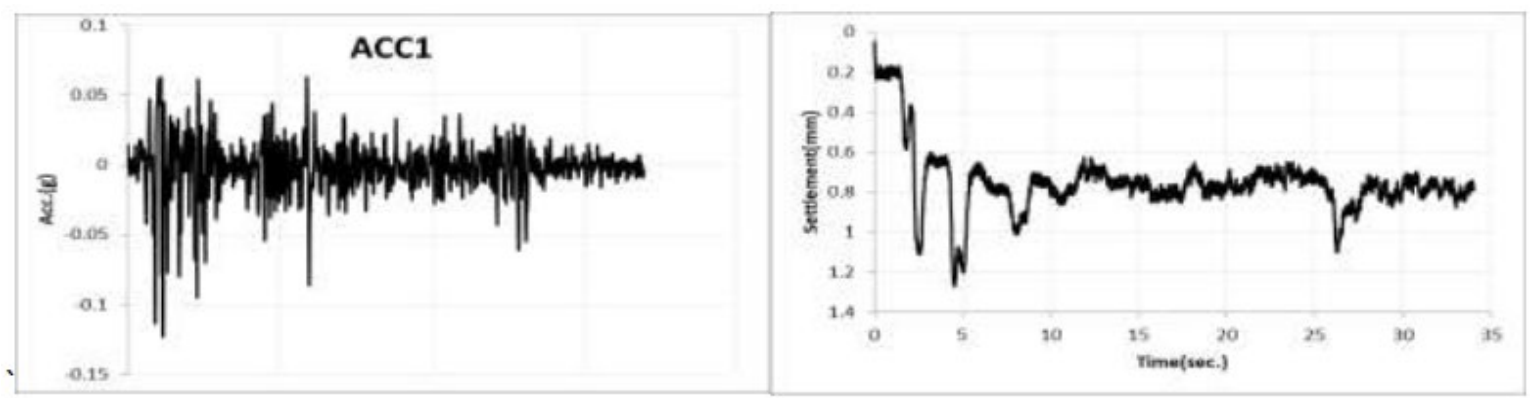

a) Tank settlement
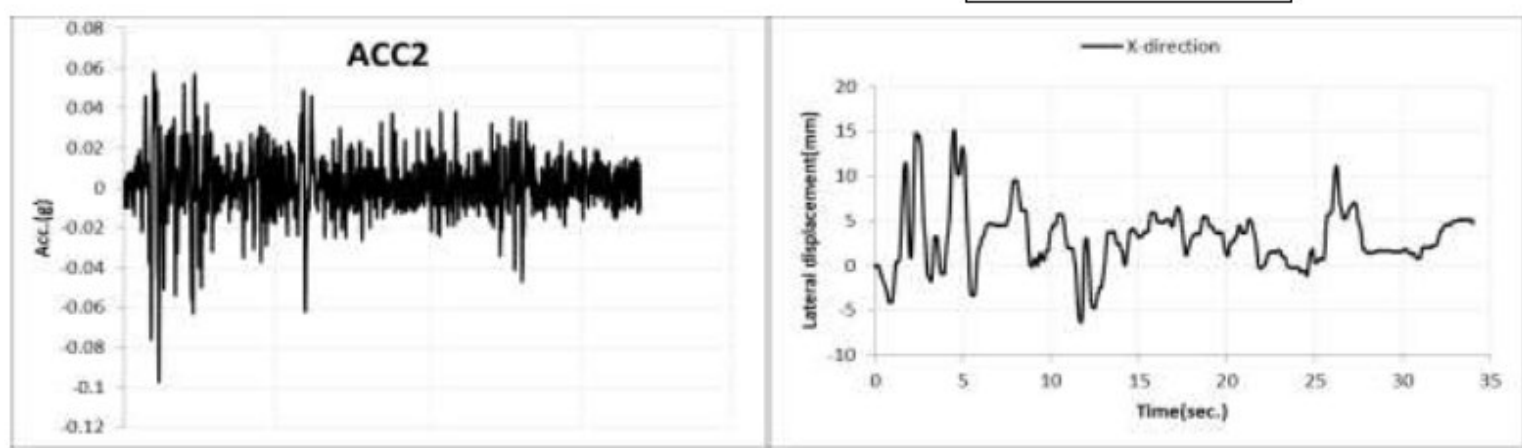

c) Tank X-lateral displacement 

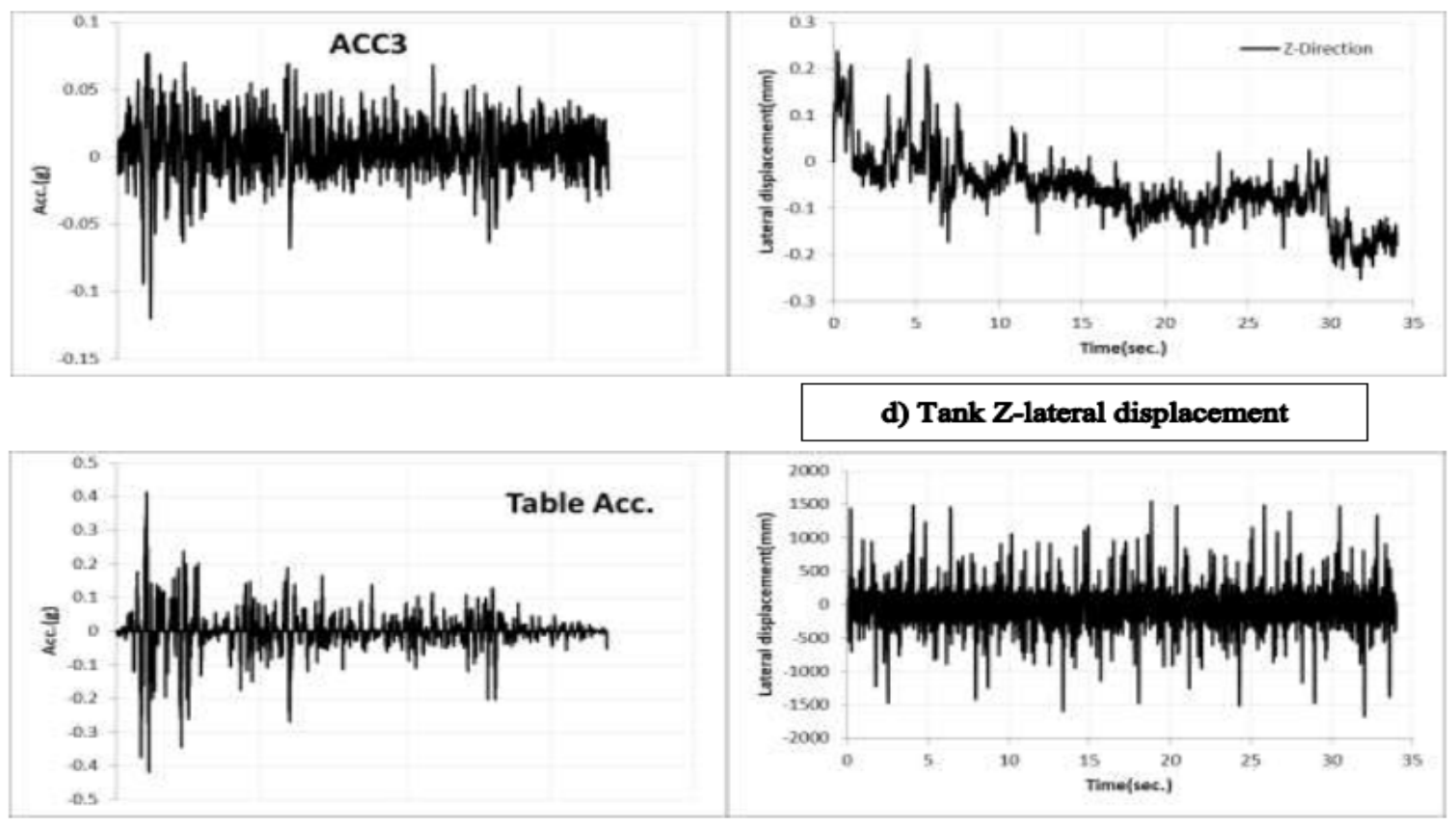

b) Acceleration

e) Tank lateral pressure at the surface

Figure 11: Results for no-Hydrodynamic El-Centro earthquake with Medium sand layer, $(\mathrm{Dr}=50 \%$, $\mathrm{ACF}=4.0)$.
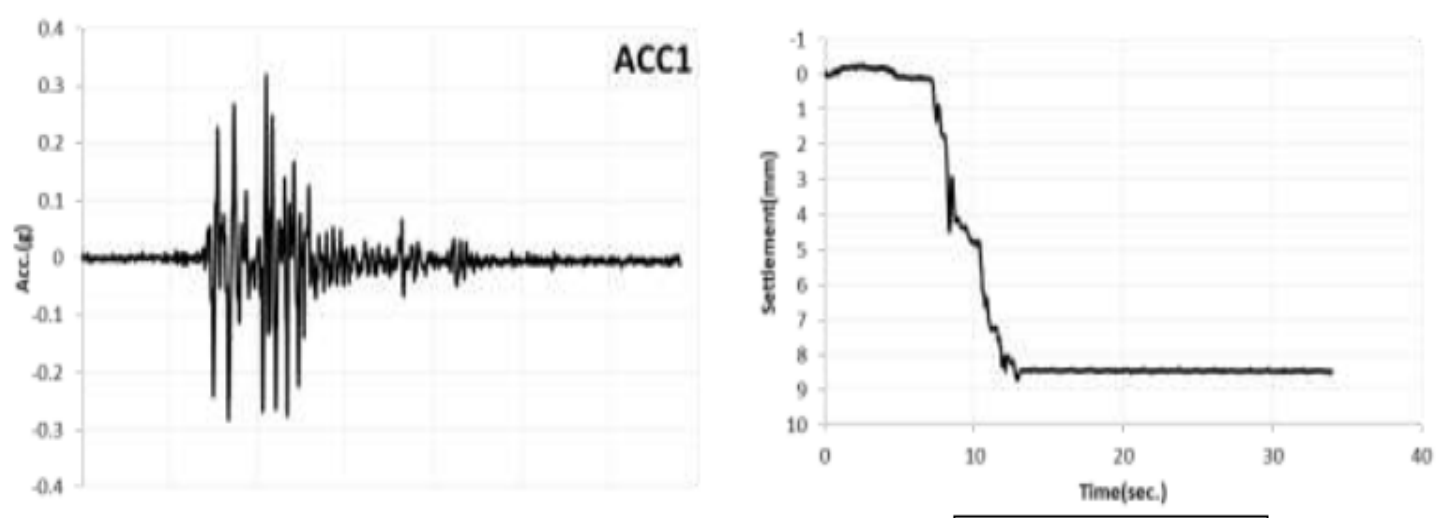

a) Tank settlement 

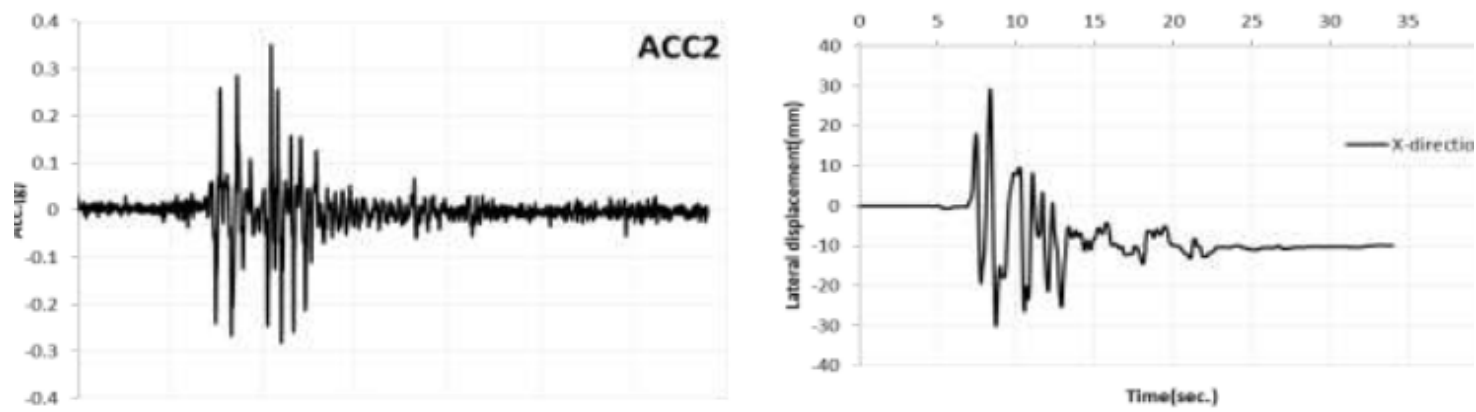

c) Tank X-lateral displacement
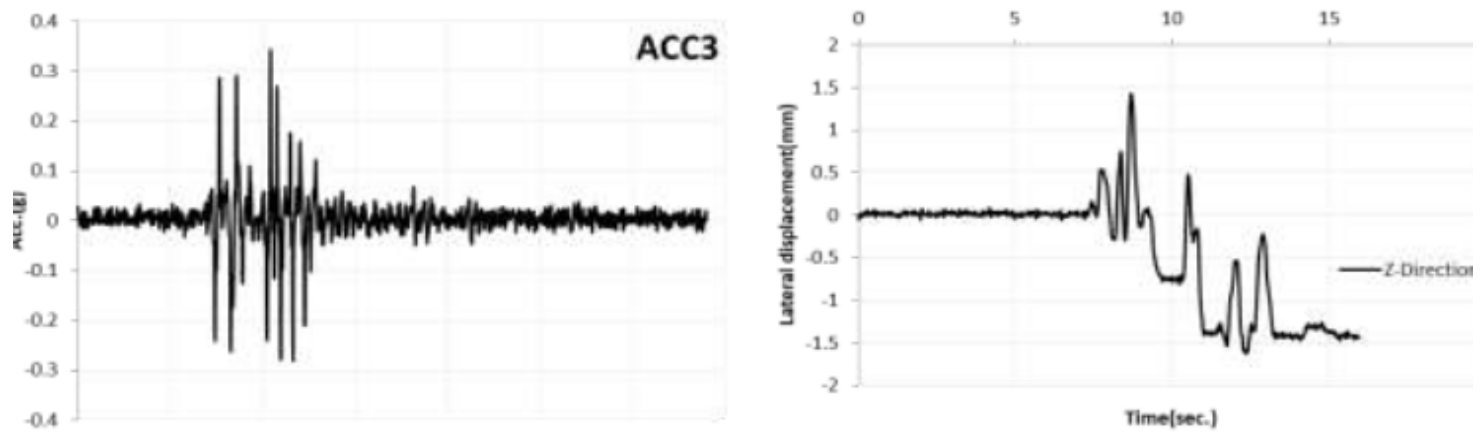

d) Tank Z-lateral displacement

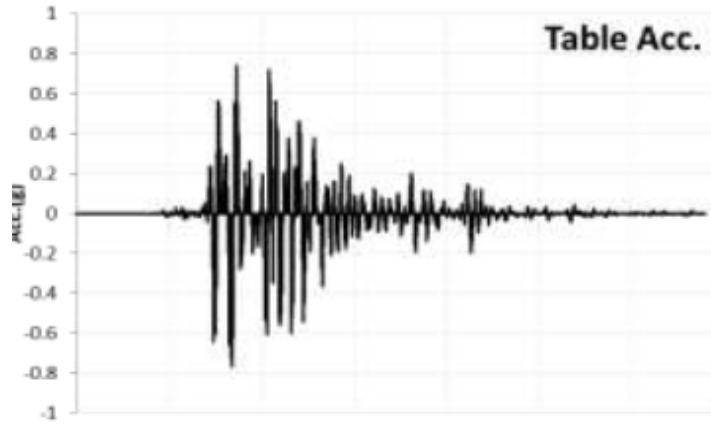

b) Acceleration

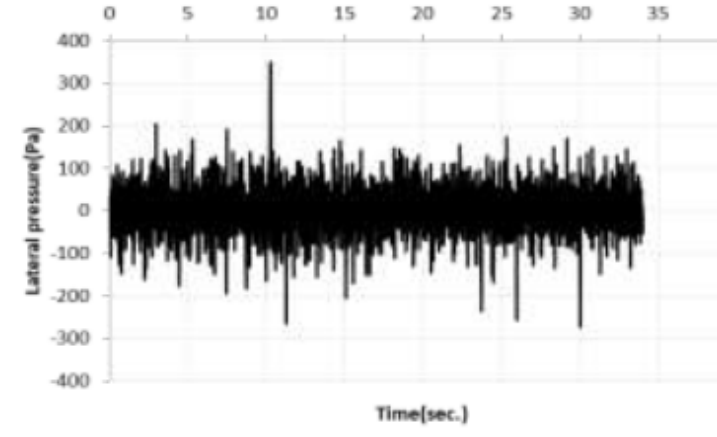

e) Tank lateral pressure at depth $=B$

Figure 12: Results for no-Hydrodynamic Kobe earthquake with Dense sand layer, (Dr=75\%, $\mathrm{ACF}=1.0$ ).

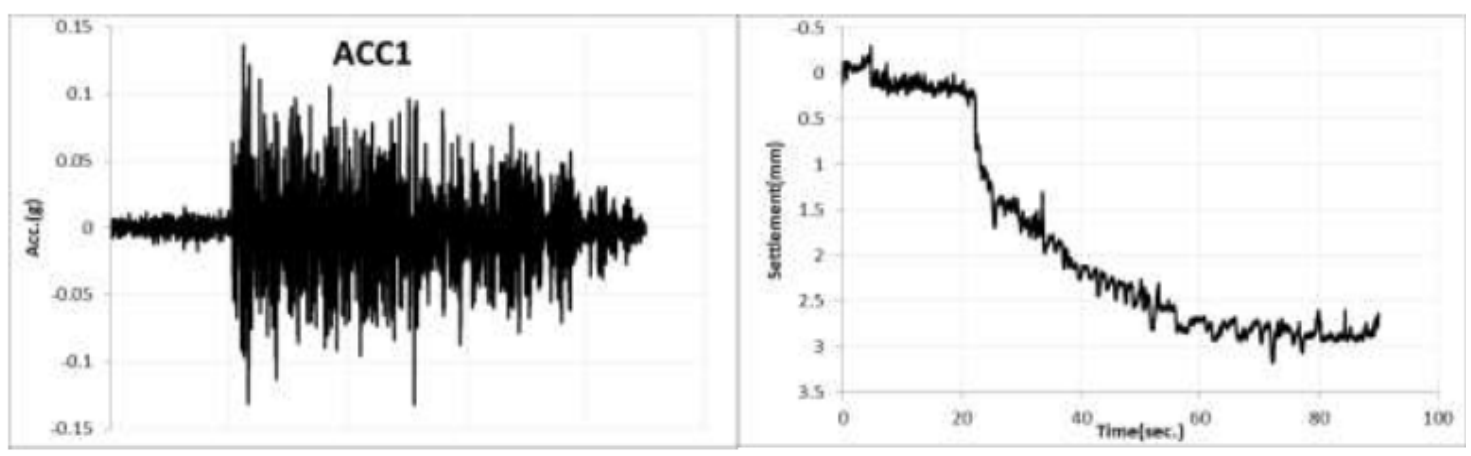




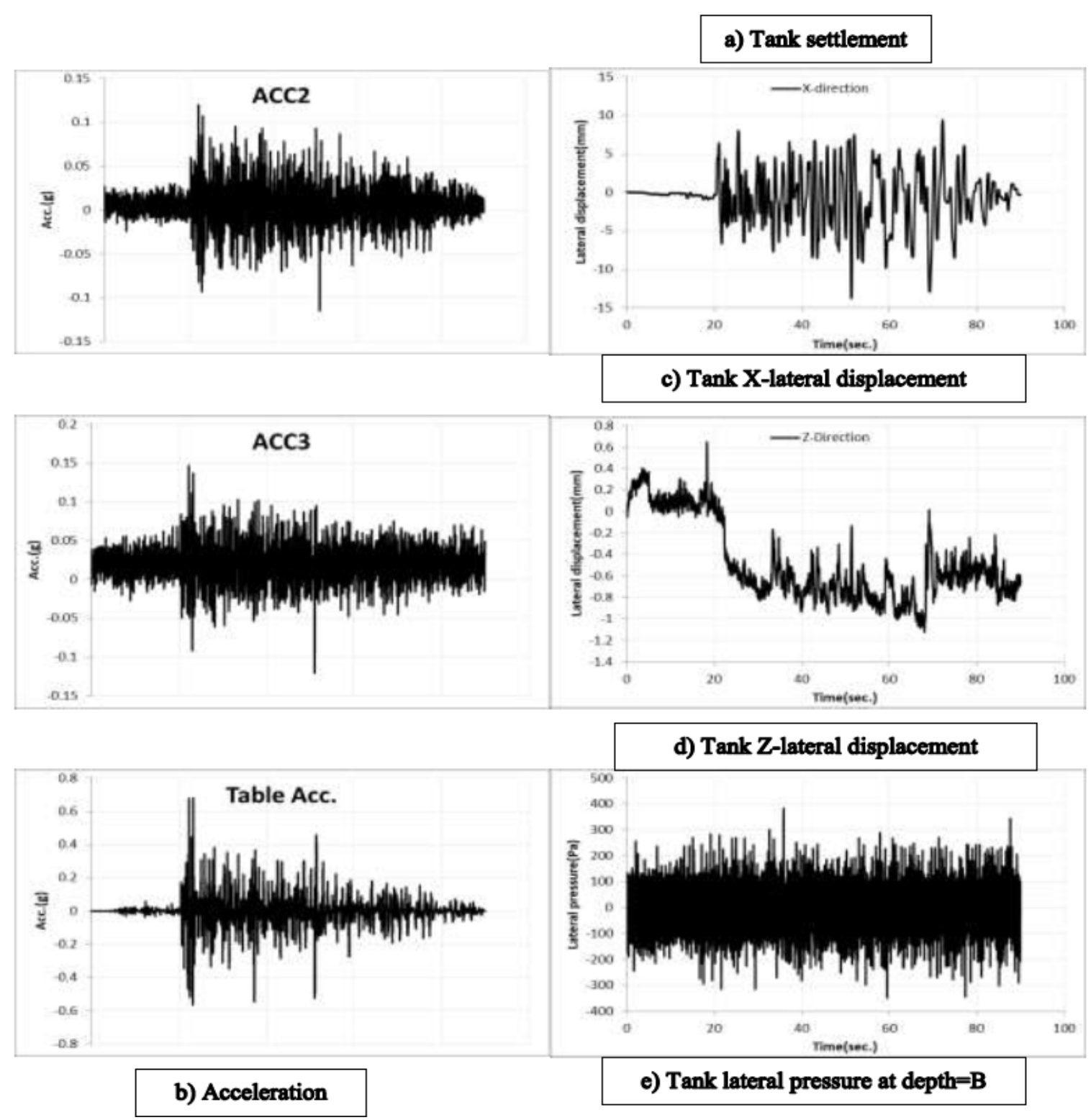

Figure 13: Results for no-Hydrodynamic Ali Al-Gharbi earthquake with Medium \& Dense sand layer, $(\mathrm{Dr}=50 \%, \mathrm{Dr}=75 \% \mathrm{ACF}=4.0)$.

\section{Influence of earthquake history}

The results of these tests were presented in Figures 8 to 13. It can be observed that the acceleration of El-Centro earthquakes inside the soil is less than the input acceleration at the table level. The acceleration at the bottom-depth of the soil column is slightly higher than at the mid-depth, while at the top portion of the soil column, the acceleration is comparatively become less than that at the mid-depth. The acceleration behaviour of Kobe in dense sand resulted in the maximum acceleration on the table, and then reduced throughout the soil column up to the surface. Ali AlGharbi earthquake gave the similar reduction in the maximum amplitude and decreasing in the frequency through the soil (Figures 10 to 13).

\section{Influence of settlement and displacement}

The settlement in hydrodynamic pressure of the storage base tank was significantly reduced compared with results of no-hydrodynamic pressure in all cases of acceleration history due to the effect of hydrodynamic pressure onto the tank wall which is turned to the tank base applying additional forces which produce an additional settlement.

Moreover, the soil unaffected due to lateral displacement in the x-direction, as a result of occurring on the axis of vibration producing the same displacement of shake history of the earthquake. A lateral displacement of z-direction was comparatively influenced by hydrodynamic 
pressure in all earthquake history (El-Centro, Kobe and Ali Al-Gharbi) due to the change in the acceleration and soil density. In addition, it was found that the soil density has an effect on the hydrodynamic pressure value which later has an influence on the results of the displacement, hence, the difference in results of displacement between hydrodynamic pressure and without hydrodynamic pressure on medium soils is greater than that of dense soils. In all soil densities, the settlement and lateral displacement in the z-direction were increased with the increasing of the acceleration amplitude and duration of shaking except in the $\mathrm{x}$-direction; it was implemented by the acceleration history.

\section{Influence of lateral stress}

The results of the lateral stress were analysed every test at the boundary of the laminar box to study the maximum lateral stress in the x-direction which is spread out due to occur on the axis of shaking. As they presented in all figures, it was indicated that the lateral stress on the surface produced a higher stress than the stress on the depth equal to the diameter of the base tank due to it is located on the maximum amplitude of the acceleration which is produced in the high shear stress.

\section{Conclusions}

In this paper, a hydrodynamic pressure on the storage tank generated during the earthquakes was investigated to study its effect on the granular soil with different relative density. Series of shake table tests were conducted to investigate the behavior of soil loaded by a cylindrical storage tank. From the analyses of the results, it was concluded that the hydrodynamic pressure has led to a great effect on the soil settlement and lateral displacement. In addition, soil density was also affected by the behavior of soil in the settlement and displacement. It was found that the amplitude of acceleration and frequency domain has led the considerable effect on settlement and lateral displacement in the z-direction. The lateral displacement in x-direction was not affected by the acceleration amplitude because it was located on the shake axis. The lateral stress was calculated at the end of the boundary of the laminar box and it showed maximum stress at the top of the soil surface compared to the lateral stress at depth B from the soil surface.

\section{REFERENCES}

[1] G. W. Housner, The dynamic behavior of water tanks, Bull. Seismol. Soc. Am. 53.2(1963) 381-387. https://doi.org/10.1785/BSSA0530020381

[2] A. S. Veletsos, Seismic effects in flexible liquid storage tanks, in Proc. 5th World Conf. Earthquake Engineering, Italy(1974) 630-639.

[3] M. A. Haroun, Dynamic Analyses of Liquid Storage Tanks, Report on research conducted under grants from the National Science Foundation, EERL., (1980)80-04.

[4] A. S. Veletsos, Tang Y. and Tang H. T., Dynamic Response of Flexibly Supported Liquid-Storage Tanks, J. Struct. Eng., 118 (1992) 264-283. https://doi.org/10.1061/(ASCE)0733-9445(1992)118:1(264)

[5] M. A. Haroun and W. Abou- Izzeddine, Parametric Study of Seismic Soil Tank Interaction, I: Horizontal Excitation, J. Struct. Eng., 118 (1992) 783-797. https://doi.org/10.1061/(ASCE)0733-9445(1992)118:3(783)

[6] J. M. Kim, S.H. Chang and C.B. Yun, Fluid- Structure- Soil Analysis of Cylindrical Liquid Storage Tanks to Horizontal Earthquake Loading, Struct. Eng. Mech., 13(2002) 615-638. https://doi.org/10.12989/sem.2002.13.6.615

[7] M. R. Kianoush and A. R. Ghaemmaghami, The effect of earthquake frequency content on the seismic behavior of concrete rectangular liquid tanks using the finite element method incorporating soil-structure interaction, Eng. Struct., 33(2011) 2186-2200. https://doi.org/10.1016/j.engstruct.2011.03.009

[8] M. Chaithra, A. Krishnamoorthy and P. M. Naurin Nafisa, Soil Structure Interaction Analysis of Tanks Filled with Fluid, Proceedings International Conference on Computational Methods in Engineering and Health Sciences, Malaysia, December 2015.

[9] M. S. Chalhoub, J. M. Kelly, Theoretical and experimental studies of cylindrical water tanks in base isolated structures. Earthquake Engineering Research Center, University of California at Berkeley, 1988.

[10] U. Chaduvula, D. Patel, N. Gopalakrishnan, Fluid-structure-soil interaction effects on seismic behavior of elevated water tanks, Procedia. Eng., 51(2013) 84-91. http://dx.doi.org/10.1016/j.proeng.2013.01.014 
[11] H. G. Poulos, and E. H. Davis, Elastic Solutions for Soil and Rock Mechanics (Soil Engineering), John. Wiley. Sons. Inc., 1974.

[12] J. Steensen-Bach, N. Foged, and J. S. Steenfelt, Capillary Induced Stresses-Fact or Fiction, Proceedings 9th European Conference on Soil Mechanics and Foundation Engineering, (1987)83-89.

[13] K. Agarwal, and M. Rana, Effect of Ground Water on Settlement of Footing in Sand, Proceedings 9th European Conference on Soil Mechanics and Foundation Engineering, (1987)751-754.

[14] M. M. Al Sammaraey, Experimental and Numerical Liquefaction Analysis of Layered Sand Soil under Shallow Spread Footing. Diss. Ph. D. Thesis., 2018. 